\title{
Estudo sobre a recorrência de teses que mencionam a utilização de tecnologias digitais em 26 Programas de Pós-Graduação em Educação no Brasil
}

\author{
Fábio Fontana Souza* \\ Maria Iolanda Monteiro ${ }^{* *}$
}

\begin{abstract}
Resumo
A proposta deste trabalho é identificar quantas teses na área de educação, disponíveis online, no período de 2002 a 2012, em vinte e seis Programas de Pós-Graduação em Educação (PPGE) de instituições com prestígio reconhecido no Brasil, mencionam a utilização de tecnologias digitais em cursos superiores presenciais de formação de professores no banco de dados do Grupo de Estudos e Pesquisas sobre Inovação em Educação, Tecnologias e Linguagens para quantificarmos o interesse acadêmico na questão de como essas possibilidades tecnológicas estão sendo apropriadas pelos referidos cursos. Para tanto recorremos à análise bibliométrica. De acordo com os resultados obtidos, em um universo de três mil quatrocentas e sessenta e nove teses de vinte e seis instituições, somente treze teses de nove instituições abordavam a questão, o que demonstra uma lacuna diante do crescimento e popularização que as tecnologias digitais sofreram ao longo do período pesquisado.
\end{abstract}

Palavras-chave: tecnologias digitais; educação; teoria crítica.

\section{Study of recurrence of theses that mention the use of digital technologies in 26 Graduate Programs in Education in Brazil}

\begin{abstract}
The purpose of this work is to identify how many theses in the area of education, available online, from 2002 to 2012, to twenty six Post-Graduate Programs in Education (PPGE) of institutions with recognized prestige in Brazil, mention the use of technologies digital presence in higher education teacher training in the database of the Group of Studies and Research on Innovation in Education, Technology and Languages for quantify the academic interest in technology as these possibilities issue station being appropriates for those courses. In order to accomplish the aims, we used bibliometric analysis. Of the agreement with the results obtained in universe three thousand four hundred sixty nine theses twenty six institutions, only thirteen theses nine institutions addressed one question, what shows shortcomings given the growth and popularization as digital technologies passed along the researched period.

Keywords: digital technologies; education; critical theory.

É muito comum nos depararmos com matérias publicadas na imprensa brasileira nas quais se afirma que o governo, tanto na esfera federal quanto estadual e municipal, tem investido na informatização das escolas, distribuindo computadores com acesso à internet por intermédio de programas como $\mathrm{UCA}^{1}$, tablets educacionais (através do Programa Nacional de Tecnologia Educacional - ProInfo Integrado - por meio do Fundo Nacional de Desenvolvimento da Educação (FNDE)), salas de informática, lousas digitais ${ }^{2}$, mídias, programas educacionais, dentre outros recursos, e equipamentos voltados para o processo de ensino e aprendizagem. Também é importante destacar a facilitação na aquisição de telefones celulares, segundo dados da Anatel $^{3}$ : o Brasil contava no mês de julho de 2013 com quase 267 milhões de linhas ativas na telefonia móvel e teledensidade $^{4}$ de 134,81 acessos por 100

habitantes. Nesse contexto grande parte dos estudantes e professores possui acesso aos equipamentos móveis 5 .

Giordan (2008) demonstra que as novas tecnologias e, em especial, o computador com acesso à internet passaram a desempenhar o papel de objetos que podem promovera inclusão e até a recriação social, visto que facilitam a armazenagem de uma enorme memória social, aproximam culturas, criam novos campos de conhecimento e dissolvem fronteiras de campos que estavam separados. É transformada a forma tanto de pensar o mundo como de agir nele.

Dessa forma, a escola, considerada como a instituição social que tem a intenção da significação dos instrumentos culturais, não poderia se afastar desses aparatos, que permitem a produção e circulação do pensamento humano, bem como de analisar criticamente todas as implicações dessa
\end{abstract}

*Doutorando/UFSCar. Endereço eletrônico: ffontanas @ hotmail.com

**Professora da UFSCar. Endereço eletrônico: iolanda.uab@gmail.com 
nova realidade.

No entanto, conforme aponta Rosa (2013), o uso das tecnologias digitais é um verdadeiro desafio para muitos professores. Não basta simplesmente o acesso aos aparatos tecnológicos. Nesse contexto, os estudos sobre a utilização das tecnologias digitais assumem uma importância vital. O nosso foco de interesse são as pesquisas que versem sobre a utilização de tecnologias digitais em cursos superiores presenciais de formação de professores.

A proposta deste trabalho é identificar quantas teses na área de educação, provenientes de instituições classificadas pela Coordenação de Aperfeiçoamento de Pessoal de Nível Superior (Capes) com nota mínima 4, disponibilizadas na internet discutem a utilização de tecnologias digitais em cursos superiores presenciais de formação de professores no banco de dados do Grupo Horizonte (Grupo de Estudos e Pesquisas sobre Inovação em Educação, Tecnologias e Linguagens), no período de 2002 a 2012. Foram pesquisadas as teses das seguintes instituições: Universidade Estadual de Campinas (UNICAMP), Universidade Federal do Rio Grande do Sul (UFRGS), Faculdade de Educação da Universidade Federal de São Paulo (FEUSP/USP), Universidade Federal do Rio Grande do Norte (UFRN), Universidade Federal de Minas Gerais (UFMG), Universidade Estadual Paulista (UNESP MARÍLIA), Universidade Federal da Bahia (UFBA), Pontifícia Universidade Católica do Rio de Janeiro (PUC-RIO), Universidade Federal de São Carlos (UFSCAR), Universidade Federal do Paraná (UFPR), Universidade do Estado do Rio de Janeiro (UERJ), Universidade Federal de Santa Catarina (UFSC), Pontifícia Universidade Católica do Rio Grande do Sul (PUC-RS), Universidade do Vale do Rio dos Sinos (UNISINOS), Universidade Federal de Goiás (UFG), Universidade Federal Fluminense (UFF), Universidade de São Paulo (USP), Universidade Metodista de Piracicaba (UNIMEP), Universidade Federal do Rio de Janeiro (UFRJ), Universidade Federal de Mato Grosso do Sul (UFMS), Universidade Federal de Uberlândia (UFU), Universidade de Brasília (UNB), Pontifícia Universidade Católica do Paraná (PUC-PR), Universidade Federal do Espírito Santo (UFES), Universidade Estadual de Maringá (UEM) e Universidade Federal de Pelotas (UFPEL).

É importante salientar que o banco de dados contém USP e FEUSP/USP.

\section{Fundamentação teórica e justificativa}

Tardif e Raymond (2000) propõem a sistematização de saberes dos professores com base nas fontes de aprendizagem que utilizaremos como fio condutor do nosso trabalho, que será exposto a seguir: saberes pessoais dos professores, estes adquiridos junto à família e com as experiências de vida; saberes provenientes da formação escolar anterior, adquiridos nos vários períodos escolares que antecedem a formação profissional, bem como nos cursos não especializados; saberes provenientes da formação profissional para o magistério, adquiridos nos cursos de formação de professores; saberes provenientes dos programas e livros didáticos usados no trabalho, oriundos da utilização de diversos materiais disponíveis como instrumentos de trabalho; saberes provenientes de sua própria experiência na profissão na sala de aula e na escola, esses adquiridos nos afazeres e socialização de experiências (TARDIF; RAYMOND, 2000).

Com relação aos primeiros contatos com as tecnologias digitais, relacionados aos saberes pessoais dos professores, nos remetemos à diferenciação geracional de Prensky (2001), que considera como "nativos digitais" os integrantes da geração que já nasceu cercada pela tecnologia, considerados especialistas digitais, aptos a utilizar várias mídias ao mesmo tempo. Segundo Mill, "esses são alunos-sujeitos de uma geração que se movimenta com facilidade e rapidez, acessando uma grande variedade de informações e com inúmeras possibilidades de comunicação e interação" (MILL, 2013, p. 5).

Em contrapartida, o termo "imigrantes digitais" é utilizado para as gerações anteriores, que acompanharam o desenvolvimento das tecnologias e que aos poucos sentiram a tecnologia sendo incorporada a sua vida cotidiana, obrigando à adaptação, às vezes contra a própria vontade. Nesse contexto, poderíamos nos deparar com várias situações, das quais destacamos professores imigrantes digitais e estudantes nativos digitais, circunstância ilustrada na matéria da Folha de São Paulo - Saber", com o título "Atual geração de professores enfrenta o desafio de aprender a mexer na internet e ensinar com poucos recursos disponíveis", na qual é descrita a situação de uma professora de 49 anos de idade, pertencente à rede pública do Rio de Janeiro, em 2011, que no início de carreira somente contava com "os livros, o quadro negro e a voz", sendo que na data da reportagem "as aulas ganharam auxílio de TV, vídeo e computador; a internet, tão conhecida dos 
alunos, aos poucos começa a fazer parte de sua rotina". Outra situação seria a deprofessores e estudantes nativos digitais, o que nos levaria a pensar se as dificuldades com a tecnologia digital utilizada com intuito de ensino e aprendizagem seriam facilmente superadas ou não. Será que o simples fato de ter nascido imerso nesse mundo digital garante o sucesso na utilização pedagógica na escola por parte dessa nova geração de professores? A resposta a essa questão não é simples e direta demandando pesquisas mais aprofundadas.

É importante salientar que nosso foco, no presente trabalho, foi a utilização de tecnologias digitas em cursos presenciais superiores de formação de professores. De acordo com Verasztoet AL (2008), tecnologia é:

Um conjunto de saberes inerentes ao desenvolvimento e concepção dos instrumentos (artefatos, sistemas, processos e ambientes) criados pelo homem através da história para satisfazer suas necessidades e requerimentos pessoais e coletivos (VERASZTO et al, 2008, p. 78).

Dessa forma, a tecnologia deve ser vista como inserida em um "quadro histórico-politico e sócio-cultural", tal qual a educação. Não podemos nos esquecer de que a vida social exige a adaptação às novas tecnologias, sendo que essa adaptação torna-se sinônimo de sobrevivência. A tecnologia deixou de ser apenas modus operandi para tornar-se modus vivendi. Ao igualar ilusoriamente o que na realidade é desigual, ela torna possível o fetiche dessa relação imprescindível para a manutenção da ordem vigente. A tecnologia, que na concepção primária deveria estar a serviço do homem, ao longo dos tempos também deu suporte para atrocidades como o nazismo, as bombas nucleares e muitas outras mazelas. Não obstante, a tecnologia também tem proporcionado muitos avanços, em especial na medicina, amainando a dor e sofrimento de um número incalculável de pessoas. Nesse contexto, temos que tentar manter uma posição equidistante dos lados extremos ao analisarmos as potencialidades e limitações das tecnologias, tal qual enunciado por Adorno (1995, p. 76) ao debater a possibilidade formativa da televisão educativa.

$\mathrm{Na}$ sala de aula estão presentes diversas tecnologias que auxiliam no processo de ensino e aprendizagem, inclusive a linguagem, considerada tecnologia intelectual, de acordo com Lévy (1993).
Dentre as tecnologias podemos destacar as digitais. Digital refere-se à "representação de dados ou informações por meio de dígitos" (SAWAYA, 1999, p. 132). Segundo Gonçalves e Canesin:

A evolução dos computadores, em conjunto com a disseminação cada vez maior da Internet (rede internacional de computadores), tornou fácil o acesso à informação, de quase todos os lugares, a qualquer hora e respeitando o ritmo do usuário. $O$ advento das tecnologias de hipermídia acompanhado por hipertextos, simulações interativas, vídeos e sons, originaram um mecanismo novo e efetivo de entrega de informações com o poder de criar laboratórios virtuais e salas de aula virtuais (2002, p.315).

Com relação aos saberes provenientes da formação escolar anterior e saberes provenientes da formação profissional para o magistério, destacamos que estes são adquiridos tanto de forma pessoal quanto na interação com os pares, inclusive utilizando como modelos os antigos professores que nos deixam marcas graças à maneira que conduziam suas aulas, como lidavam com as dificuldades, como utilizavam diversos recursos, a entonação de voz, os exemplos em aula, dentre outras vivências que ao longo do tempo foram se convertendo em experiências que nos influenciam na prática em sala de aula. Aprendemos a utilizar as tecnologias educativas, inclusive as digitais, tanto no dia a dia da escola ao acompanharmos o uso dos diversos recursos tecnológicos por parte dos professores quando elas são objeto de estudo em disciplinas específicas.

Por fim, com relação à socialização de experiências docentes mediadas pelas tecnologias, podemos pensar tanto nos programas tutoriais que buscam difundir as formas de utilização das tecnologias digitais nas classes quanto na divulgação de experiências bem sucedidas.

De acordo com o exposto, o aprendizado docente para a utilização das tecnologias digitais no processo de ensino e aprendizagem depende de uma série de fatores, dos quais foram mencionados alguns, nas linhas mais acima, utilizando como fio condutor a sistematização dos saberes apresentada por Tardif e Raymond (2000) e, nesse contexto, reputamos de importância capital as pesquisas em educação e, em especial, as realizadas nos programas de pós-graduação em educação. Segundo 
Garnica (1997, p. 121), "pesquisar é mostrar-se. Pesquisar é um exercício para compreendermos o mundo". A pesquisa não deve ser entendida como algo isolado e sim como um processo de aprendizado para o pesquisador, que tem a oportunidade de desenvolver conhecimentos que serão úteis para a sociedade. Com esse intuito buscamos identificar quantas teses na área de educação do banco de dados do Grupo Horizonte mencionam a utilização de tecnologias digitais em cursos superiores presenciais de formação de professores.

\section{Procedimentos metodológicos}

Como ponto de partida foi realizado um levantamento de teses catalogadas digitalmente e disponíveis online, produzidas no período de 2002 a 2012 em vinte e seis Programas de Pós-Graduação em Educação (PPGE) de instituições com prestígio reconhecido no Brasil. Foram levantadas as seguintes informações:

- Instituição em que a tese foi defendida

- Ano da defesa

- Autoria

- Título da tese

- Termos chave

- Resumo da tese

- Link da tese (quando disponível)

Essas informações serviram de base para a construção coletiva de um banco de dados do Grupo Horizonte. O quadro 01 registra a relação do número de teses levantadas por instituição, possibilitando a visualização da quantidade de teses na área de educação, produzidas nos PPGEs.

Relação do número de teses levantadas por instituição:

Quadro 01: Quantitativo de teses por PPGE, ano de criação do programa e nota CAPES

\begin{tabular}{|c|c|c|c|}
\hline IES & Qtde de Teses & $\begin{array}{l}\text { Ano de criação do programa de } \\
\text { Doutorado }\end{array}$ & $\begin{array}{l}\text { Nota PPGE na } \\
\text { CAPES }\end{array}$ \\
\hline UNICAMP & 710 & 1980 & 5 \\
\hline UFRGS & 416 & 1976 & 5 \\
\hline FEUSP/USP & 372 & 1971 & 6 \\
\hline UFRN & 227 & 1994 & 5 \\
\hline UFMG & 226 & 1971 & 7 \\
\hline UNESP MARÍLIA & 172 & 1993 & 4 \\
\hline UFBA & 129 & 1992 & 4 \\
\hline PUC-RIO & 115 & 1976 & 7 \\
\hline UFSCAR & 112 & 1991 & 5 \\
\hline UFPR & 112 & 2001 & 5 \\
\hline UERJ & 103 & 2002 & 7 \\
\hline UFSC & 90 & 1994 & 4 \\
\hline PUC-RS & 88 & 1989 & 6 \\
\hline UNISINOS & 88 & 1999 & 6 \\
\hline UFG & 86 & 2001 & 5 \\
\hline UFF & 83 & 1995 & 6 \\
\hline USP & 65 & 1971 & 6 \\
\hline UNIMEP & 62 & 1992 & 5 \\
\hline UFRJ & 47 & 1980 & 5 \\
\hline UFMS & 43 & 1991 & 7 \\
\hline UFU & 35 & 2006 & 5 \\
\hline UNB & 22 & 2005 & 4 \\
\hline PUC-PR & 20 & 2007 & 4 \\
\hline UFES & 19 & 2004 & 5 \\
\hline UEM & 17 & 2007 & 4 \\
\hline UFPEL & 10 & 2006 & 5 \\
\hline Total & 3469 & & \\
\hline
\end{tabular}

Fonte: Elaborada pelos autores. 
Ao todo foram contabilizadas 3469 teses, sendo que UNICAMP foi a instituição que apresentou maior número de teses, 710 teses ao total, e a UFPEL o menor, totalizando 10 teses. É importante mencionar que a UNICAMP conta com programa de doutorado em educação desde 1980, conforme informações da página do programa na internet, ao passo que a UFPEL inicia o programa de doutorado em educação no ano de 2006, conforme pode ser observado no quadro 01 .

Quadro 02: Quantidade de teses por ano

\begin{tabular}{|l|r|}
\hline ANO & Quantidade de Teses \\
\hline 2002 & 98 \\
\hline 2003 & 148 \\
\hline 2004 & 154 \\
\hline 2005 & 225 \\
\hline 2006 & 303 \\
\hline 2007 & 369 \\
\hline 2008 & 459 \\
\hline 2009 & 467 \\
\hline 2010 & 461 \\
\hline 2011 & 386 \\
\hline 2012 & 399 \\
\hline Total & $\mathbf{3 4 6 9}$ \\
\hline
\end{tabular}

Fonte: Elaborada pelos autores.

Segundo Souza (2013, p. 6), no Brasil, na metade da década de 90 do século passado, com a atuação conjunta dos Ministérios da Comunicação e de Ciências e Tecnologia, implantou-se a infraestrutura para rede de internet e a regulamentação jurídica necessária, sendo que principalmente na década seguinte, ou seja, a partir dos anos 2000, com o aumento do número de acessos de empresas e instituições, estas passaram a disponibilizar informações online com o auxílio da criação de bancos de dados integrados a formulários web, motivo pelo qual observamos um número menor de teses nos primeiros anos contemplados no quadro 02. Destarte, a maioria das instituições constituíram bancos digitais de teses nos primeiros anos do século atual.

Com relação à queda do número de teses nos últimos anos catalogados no banco de dados, podemos atribui-lo ao fato da não disponibilização dos trabalhos mais recentes para a publicação digital, sendo importante salientar também que o autor de uma tese pode estipular a data de publicação digital de seu trabalho.

\section{Sistematização e análise das teses}

O nosso objetivo foi delimitar quantas teses estavam relacionadas com a formação de professores e, destas teses, quantas mencionavam recursos digitais em cursos presenciais. Iniciamos a pesquisa demarcando quantas estavam relacionadas à formação de professores com a utilização dos termos-chave das teses. Pesquisamos os seguintes termos:

- Formação inicial,

- Licenciatura,

- Formação do pedagogo,

- Presencial,

- Formação de professores,

- Formação docente.

A busca foi realizada nos termos-chave da tabela denominada "Teses" do arquivo "Base de teses - alunos", criada a partir de dados coletados coletivamente pelo grupo Grupo Horizonte (Grupo de Estudos e Pesquisas sobre Inovação em Educação, Tecnologias e Linguagens), com auxílio do software Access da Microsoft, cuja função é a criação e gerenciamento de banco de dados. Obtivemos um total de 338 ocorrências coletadas em 26 instituições de educação superior de acordo com o quadro 03 . 
Quadro 03: Ocorrência dos termos chave

\begin{tabular}{|l|c|}
\hline \multicolumn{1}{|c|}{ Termo chave } & Ocorrência (teses) \\
\hline Formação de professores & 236 \\
\hline Formação do pedagogo & 1 \\
\hline Formação docente & 47 \\
\hline Formação Inicial & 25 \\
\hline Licenciatura & 27 \\
\hline Presencial & 2 \\
\hline Total & $\mathbf{3 3 8}$ \\
\hline
\end{tabular}

Fonte: Elaborada pelos autores.

A partir das 338 teses selecionadas com base nos termos chave, passamos a selecionar nos resumos os seguintes termos: Tecnologia, Presencial, TIC, Internet, Mídia, CD/DVDs, Vídeo, Recursos, Virtual, Ambiente, Computador, Tablet, Web e Digital, termos esses relacionados às tecnologias digitais. Inicialmente fizemos as buscas por termos e em sequência; após a leitura dos resumos, realizamos a seleção. Com o uso do termo "tecnologia", buscamos teses que tratem de tecnologias digitais; presencial, teses que versem sobre educação presencial; TIC e suas variações (TICs, TDIC). A respeito do termo TDIC (Tecnologias Digitais da Informação e Comunicação), Valente (2005) aduz que abrange a conexão de diversas mídias e, nesse sentido, Afonso (2002) recomenda a utilização do termo diferenciando TIC, que existe "desde tempos imemoriais", ao invés de TDIC, "um fenômeno que se consolidou na última década do século XX" (p. 169). O termo "internet" foi pesquisado nos resumos pela possibilidade de estar relacionado a diversas tecnologias digitais, em especial ambientes virtuais de ensino e aprendizagem, bem como os termos Mídia, CD/DVDs, Vídeo, Recursos, Virtual, Ambiente, Computador, Tablet, Web e Digital.

Obtivemos um total de 116 teses, cujos resumos continham as palavras acima mencionadas, conforme o quadro a seguir.

Quadro 04: Ocorrência termos pesquisados nos resumos

\begin{tabular}{|l|r|}
\hline \multicolumn{1}{|c|}{ Termos pesquisados nos resumos } & Ocorrências (teses) \\
\hline Ambiente & 28 \\
\hline Computador & 4 \\
\hline Digital & 5 \\
\hline Internet & 3 \\
\hline Mídia & 11 \\
\hline Presencial & 12 \\
\hline Recursos & 18 \\
\hline Tecnologia & 25 \\
\hline TIC/TIDIC/CD/DVD/vídeo/tablet/celular/smartfone & 0 \\
\hline Virtual & 3 \\
\hline Web & 6 \\
\hline Total & $\mathbf{1 1 6}$ \\
\hline
\end{tabular}

Fonte: Elaborada pelos autores.

A seguir passamos à leitura detalhada dos resumos das teses selecionadas com o intuito de verificar quais mencionam a utilização de tecnologias digitais nos cursos superiores presenciais de formação de professores.

Com base na leitura dos resumos, selecionamos as teses expostas nos quadros a seguir. É importante mencionar que algumas teses irão aparecer repetidamente, uma vez que o segundo filtro foi feito nos resumos selecionados por termoschave, e assim cada seleção poderia conter repetidamente as teses selecionadas anteriormente. A exclusão de teses repetidas foi feita na fase final do trabalho; com isso buscamos garantir um grau maior de precisão na seleção final das teses.

Das teses que continham no resumo o termo "ambiente" , foram selecionadas: 
Quadro 05: Teses que continham no resumo o termo Ambiente

\begin{tabular}{|l|c|l|l|}
\hline \multicolumn{1}{|c|}{ IES } & ANO & \multicolumn{1}{c|}{ TÍTULO DA TESE } & $\begin{array}{c}\text { AUTOR (A) DA } \\
\text { TESE }\end{array}$ \\
\hline $\begin{array}{l}\text { UNESP } \\
\text { Marília }\end{array}$ & 2005 & $\begin{array}{l}\text { O programa PEC/Formação Universitária: paradigma para a qualificação docente na } \\
\text { Idade Mídia }\end{array}$ & $\begin{array}{l}\text { Elisio Vieira de } \\
\text { Faria }\end{array}$ \\
\hline UNB & 2009 & $\begin{array}{l}\text { Os papéis docentes nas situações de webconferência um estudo de caso acerca da } \\
\text { ação educativa presencial conectada }\end{array}$ & $\begin{array}{l}\text { Francisco Vieira } \\
\text { Garonce }\end{array}$ \\
\hline UFPR & 2011 & $\begin{array}{l}\text { O papel do professor na formação do pensamento matemático de estudantes durante } \\
\text { a construção de provas em um ambiente de geometria dinâmica }\end{array}$ & $\begin{array}{l}\text { Elen Andrea } \\
\text { Janzen }\end{array}$ \\
\hline
\end{tabular}

Fonte: Elaborada pelos autores.

Selecionamos 3 teses distribuídas por IES distintas no período compreendido entre 2005 a 2011.

Das teses que continham no resumo o termo "computador" foram selecionadas:

Quadro 06: Teses que continham no resumo o termo Computador

\begin{tabular}{|l|c|l|l|}
\hline \multicolumn{1}{|c|}{ IES } & ANO & \multicolumn{1}{c|}{ TÍTULO DA TESE } & \multicolumn{1}{c|}{ AUTOR (A) DA TESE } \\
\hline UERJ & 2012 & $\begin{array}{l}\text { Comunicação alternativa e formação inicial de professores para a } \\
\text { escola inclusiva. }\end{array}$ & Carolina RizzottoSchirmer \\
\hline UFBA & 2008 & $\begin{array}{l}\text { A formação de professores e a utilização das tecnologias de } \\
\text { informação e comunicação nos cursos de licenciatura da } \\
\text { Universidade do Estado da Bahia Campus II - Alagoinhas - Bahia }\end{array}$ & $\begin{array}{l}\text { Daisy Oliveira da Costa Lima } \\
\text { Fonseca }\end{array}$ \\
\hline PUC-Rio & 2010 & $\begin{array}{l}\text { Letramento digital: um estudo sobre a formação de discentes do } \\
\text { curso de letras da UEPA }\end{array}$ & Elisa Maria Pinheiro de Souza \\
\hline
\end{tabular}

Fonte: Elaborada pelos autores.

Selecionamos 3 teses distribuídas por IES distintas no período compreendido entre 2008 a 2012.

Das teses que continham no resumo o termo "internet" foram selecionadas:

Quadro 07: Teses que continham no resumo o termo Internet

\begin{tabular}{|c|c|l|l|}
\hline \multicolumn{1}{|c|}{ IES } & ANO & \multicolumn{1}{|c|}{ TÍTULO DA TESE } & \multicolumn{1}{c|}{ AUTOR (A) DA TESE } \\
\hline UFBA & 2008 & $\begin{array}{l}\text { A formação de professores e a utilização das tecnologias de } \\
\text { informação e comunicação nos cursos de licenciatura da } \\
\text { Universidade do Estado da Bahia Campus II - Alagoinhas - Bahia }\end{array}$ & $\begin{array}{l}\text { Daisy Oliveira da Costa Lima } \\
\text { Fonseca }\end{array}$ \\
\hline UNB & 2009 & $\begin{array}{l}\text { Os papéis docentes nas situações de webconferência um estudo de } \\
\text { caso acerca da ação educativa presencial conectada }\end{array}$ & Francisco Vieira Garonce \\
\hline
\end{tabular}

Fonte: Elaborada pelos autores.

Selecionamos 2 teses distribuídas por IES distintas no período compreendido entre 2008 e 2009 .

Das teses que continham no resumo o termo "digital" foram selecionadas:

Quadro 08: Teses que continham no resumo o termo digital

\begin{tabular}{|l|c|l|l|}
\hline IES & ANO & TÍTULO DA TESE & AUTOR (A) DA TESE \\
\hline PUC-Rio & 2010 & $\begin{array}{l}\text { Letramento digital: um estudo sobre a formação de discentes do } \\
\text { curso de letras da UEPA }\end{array}$ & Elisa Maria Pinheiro de Souza \\
\hline
\end{tabular}

$$
\text { Fonte: Elaborada pelos autores. }
$$

Selecionamos somente 1 tese no ano de 2010.

Das teses que continham no resumo o termo "mídia" foram selecionadas: 
Quadro 09: Teses que continham no resumo o termo Mídia

\begin{tabular}{|l|r|l|l|}
\hline \multicolumn{1}{|c|}{ IES } & \multicolumn{1}{c|}{ ANO } & \multicolumn{1}{|c|}{ TÍTULO DA TESE } & \multicolumn{1}{c|}{ AUTOR (A) DA TESE } \\
\hline USP & 2012 & $\begin{array}{l}\text { Um diálogo entre comunicação e educação: a formação inicial de } \\
\text { professores em sociedades midiáticas }\end{array}$ & Simone Rodrigues Batista \\
\hline $\begin{array}{l}\text { UNESP } \\
\text { Marília }\end{array}$ & 2005 & $\begin{array}{l}\text { O programa PEC/Formação Universitária: paradigma para a } \\
\text { qualificação docente na Idade Mídia }\end{array}$ & Elisio Vieira de Faria \\
\hline PUC-Rio & 2010 & $\begin{array}{l}\text { Letramento digital: um estudo sobre a formação de discentes do } \\
\text { curso de letras da UEPA }\end{array}$ & Elisa Maria Pinheiro de Souza \\
\hline UFRN & 2011 & $\begin{array}{l}\text { O lugar do estudo das mídias na formação de professores numa } \\
\text { perspectiva emancipatória }\end{array}$ & Márcia Barbosa da Silva \\
\hline UFRN & 2011 & $\begin{array}{l}\text { Entre telas, diálogos e estratégias: formação docente para a mídia } \\
\text { televisiva }\end{array}$ & Sandro da Silva Cordeiro \\
\hline
\end{tabular}

Fonte: Elaborada pelos autores.

Selecionamos 5 teses distribuídas por 4 IES distintas no período compreendido entre 2005 a 2012.

Das teses que continham no resumo o termo "Presencial" foram selecionadas:

Quadro 10: Teses que continham no resumo o termo Presencial

\begin{tabular}{|l|r|l|l|}
\hline \multicolumn{1}{|c|}{ IES } & ANO & \multicolumn{1}{|c|}{ TÍTULO DA TESE } & \multicolumn{1}{c|}{ AUTOR (A) DA TESE } \\
\hline UNB & 2009 & $\begin{array}{l}\text { Os papéis docentes nas situações de webconferência um estudo de } \\
\text { caso acerca da ação educativa presencial conectada }\end{array}$ & Francisco Vieira Garonce \\
\hline $\begin{array}{l}\text { UNESP } \\
\text { Marília }\end{array}$ & 2005 & $\begin{array}{l}\text { O programa PEC/Formação Universitária: paradigma para a } \\
\text { qualificação docente na Idade Mídia }\end{array}$ & Elisio Vieira de Faria \\
\hline UFBA & 2006 & $\begin{array}{l}\text { Mediações na formação a distância de professores: autonomia, } \\
\text { comunicação e prática pedagógica }\end{array}$ & $\begin{array}{l}\text { Cleide Aparecida Carvalho } \\
\text { Rodrigues }\end{array}$ \\
\hline UNICAMP & 2011 & $\begin{array}{l}\text { Autoeficácia de professores para utilizarem tecnologias de } \\
\text { informática no ensino }\end{array}$ & $\begin{array}{l}\text { Cacilda Encarnação Augusto } \\
\text { Alvarenga }\end{array}$ \\
\hline
\end{tabular}

Fonte: Elaborada pelos autores.

Selecionamos 4 teses distribuídas por 4 IES distintas no período compreendido entre 2005 a 2011 .

Das teses que continham no resumo o termo "Recursos" foram selecionadas:

Quadro 11: Teses que continham no resumo o termo Recursos

\begin{tabular}{|l|c|l|l|}
\hline \multicolumn{1}{|c|}{ IES } & ANO & \multicolumn{1}{|c|}{ TÍTULO DA TESE } & \multicolumn{1}{|c|}{ AUTOR (A) DA TESE } \\
\hline UERJ & 2012 & $\begin{array}{l}\text { Comunicação alternativa e formação inicial de professores para a } \\
\text { escola inclusiva. }\end{array}$ & Carolina RizzottoSchirmer \\
\hline $\begin{array}{l}\text { UNESP } \\
\text { Marília }\end{array}$ & 2005 & $\begin{array}{l}\text { O programa PEC/Formação Universitária: paradigma para a } \\
\text { qualificação docente na Idade Mídia }\end{array}$ & Elisio Vieira de Faria \\
\hline $\begin{array}{l}\text { UNESP } \\
\text { Marília }\end{array}$ & 2012 & $\begin{array}{l}\text { Formação de professores de salas de recursos multifuncionais para } \\
\text { o uso de tecnologia assistiva }\end{array}$ & Eromi Izabel Hummel \\
\hline FEUSP/USP & 2009 & $\begin{array}{l}\text { A prática da pesquisa e mapeamento informacional bibliográfico } \\
\text { apoiados por recursos tecnológicos: impactos na formação de } \\
\text { professores }\end{array}$ & Claudio Fernando André \\
\hline
\end{tabular}

Fonte: Elaborada pelos autores.

Selecionamos 4 teses distribuídas por 3 IES distintas no período compreendido entre 2005 a 2012.

Das teses que continham no resumo o termo "tecnologia" foram selecionadas: 
Quadro 12: Teses que continham no resumo o termo Tecnologia

\begin{tabular}{|l|c|l|l|}
\hline \multicolumn{1}{|c|}{ IES } & ANO & \multicolumn{1}{|c|}{ TíTULO DA TESE } & AUTOR (A) DA TESE \\
\hline UERJ & 2012 & $\begin{array}{l}\text { Comunicação alternativa e formação inicial de professores para a } \\
\text { escola inclusiva. }\end{array}$ & Carolina RizzottoSchirmer \\
\hline USP & 2012 & $\begin{array}{l}\text { Um diálogo entre comunicação e educação: a formação inicial de } \\
\text { professores em sociedades midiáticas }\end{array}$ & Simone Rodrigues Batista \\
\hline UFBA & 2008 & $\begin{array}{l}\text { A formação de professores e a utilização das tecnologias de } \\
\text { informação e comunicação nos cursos de licenciatura da } \\
\text { Universidade do Estado da Bahia Campus II - Alagoinhas - Bahia }\end{array}$ & $\begin{array}{l}\text { Daisy Oliveira da Costa Lima } \\
\text { Fonseca }\end{array}$ \\
\hline UNB & 2009 & $\begin{array}{l}\text { Os papéis docentes nas situaçães de webconferência um estudo de } \\
\text { caso acerca da ação educativa presencial conectada }\end{array}$ & Francisco Vieira Garonce \\
\hline UNB & 2009 & $\begin{array}{l}\text { A formação inicial de professores on-line: possibilidades, } \\
\text { contradições e desafios : 2000-2005 }\end{array}$ & Fábia Magali Santos Vieira \\
\hline $\begin{array}{l}\text { UNESP } \\
\text { Marília }\end{array}$ & 2005 & $\begin{array}{l}\text { O programa PEC/Formação Universitária: paradigma para a } \\
\text { qualificação docente na Idade Mídia }\end{array}$ & Elisio Vieira de Faria \\
\hline $\begin{array}{l}\text { UNESP } \\
\text { Marília }\end{array}$ & 2012 & $\begin{array}{l}\text { Formação de professores de salas de recursos multifuncionais para o } \\
\text { uso de tecnologia assistiva }\end{array}$ & Eromi Izabel Hummel \\
\hline FEUSP/USP & 2009 & $\begin{array}{l}\text { A prática da pesquisa e mapeamento informacional bibliográfico } \\
\text { apoiados por recursos tecnológicos: impactos na formação de } \\
\text { professores }\end{array}$ & Claudio Fernando André. \\
\hline UNICAMP & 2006 & $\begin{array}{l}\text { A escrita no processo de formação continua do professor de } \\
\text { matemática }\end{array}$ & $\begin{array}{l}\text { Maria Teresa Menezes } \\
\text { Freitas }\end{array}$ \\
\hline PUC-Rio & 2010 & $\begin{array}{l}\text { Letramento digital: um estudo sobre a formação de discentes do } \\
\text { curso de letras da UEPA }\end{array}$ & $\begin{array}{l}\text { Elisa Maria Pinheiro de } \\
\text { Souza }\end{array}$ \\
\hline UERJ & 2008 & $\begin{array}{l}\text { Formação e trabalho docente: os sentidos atribuídos às tecnologias } \\
\text { da informação e da comunicação }\end{array}$ & $\begin{array}{l}\text { Ligia Karam Corrêa de } \\
\text { Magalhães }\end{array}$ \\
\hline UFPR & 2011 & $\begin{array}{l}\text { O papel do professor na formação do pensamento matemático de } \\
\text { estudantes durante a construção de provas em um ambiente de } \\
\text { geometria dinâmica }\end{array}$ & Elen Andrea Janzen \\
\hline
\end{tabular}

Fonte: Elaborada pelos autores.

Selecionamos 12 teses distribuídas por 9 IES distintas no período compreendido entre 2005 a 2012.

Das teses que continham no resumo o termo "virtual" foram selecionadas:

Quadro 13: Teses que continham no resumo o termo virtual

\begin{tabular}{|l|l|l|l|}
\hline IES & ANO & TÍTULO DA TESE & AUTOR (A) DA TESE \\
\hline UFRGS & 2010 & $\begin{array}{l}\text { Educação a distância e racionalidade comunicativa: a construção } \\
\text { do entendimento na comunidade virtual de aprendizagem }\end{array}$ & Silvestre Novak \\
\hline UNB & 2009 & $\begin{array}{l}\text { Os papéis docentes nas situações de webconferência um estudo de } \\
\text { caso acerca da ação educativa presencial conectada }\end{array}$ & Francisco Vieira Garonce \\
\hline
\end{tabular}

Fonte: Elaborada pelos autores.

Selecionamos 2 teses distribuídas por 2 IES distintas no período compreendido entre 2009 a 2010.

Das teses que continham no resumo o termo " $W e b$ " foram selecionadas:

Quadro 14: Teses que continham no resumo o termo Web

\begin{tabular}{|l|c|l|l|}
\hline \multicolumn{1}{|c|}{ IES } & ANO & \multicolumn{1}{|c|}{ TÍTULO DA TESE } & \multicolumn{1}{|c|}{ AUTOR (A) DA TESE } \\
\hline UFBA & 2008 & $\begin{array}{l}\text { A formação de professores e a utilização das tecnologias de } \\
\text { informação e comunicação nos cursos de licenciatura da } \\
\text { Universidade do Estado da Bahia Campus II - Alagoinhas - Bahia }\end{array}$ & $\begin{array}{l}\text { Daisy Oliveira da Costa Lima } \\
\text { Fonseca }\end{array}$ \\
\hline UNB & 2009 & $\begin{array}{l}\text { Os papéis docentes nas situações de webconferência um estudo de } \\
\text { caso acerca da ação educativa presencial conectada }\end{array}$ & Francisco Vieira Garonce \\
\hline FEUSP/USP & 2009 & $\begin{array}{l}\text { A prática da pesquisa e mapeamento informacional bibliográfico } \\
\text { apoiados por recursos tecnológicos: impactos na formação de } \\
\text { professores }\end{array}$ & Claudio Fernando André. \\
\hline
\end{tabular}

Fonte: Elaborada pelos autores. 
Selecionamos 3 teses distribuídas por 3 IES distintas no período compreendido entre 2008 a 2009.

Com a exclusão das teses repetidas, foram selecionadas 13 teses que mencionam a utilização de tecnologias digitais nos cursos superiores presenciais de formação de professores, conforme o quadro 15.

Quadro 15: Teses que versam sobre as tecnologias digitais presentes cursos presenciais superiores de formação de professores

\begin{tabular}{|c|c|c|c|}
\hline IES & ANO & TÍTULO DA TESE & AUTOR (A) DA TESE \\
\hline $\begin{array}{l}\text { UNESP } \\
\text { Marília }\end{array}$ & 2005 & $\begin{array}{l}\text { O programa PEC/Formação Universitária: paradigma para a } \\
\text { qualificação docente na Idade Mídia }\end{array}$ & Elisio Vieira de Faria \\
\hline UNB & 2009 & $\begin{array}{l}\text { Os papéis docentes nas situações de webconferência um estudo } \\
\text { de caso acerca da ação educativa presencial conectada }\end{array}$ & Francisco Vieira Garonce \\
\hline UFPR & 2011 & $\begin{array}{l}\text { O papel do professor na formação do pensamento matemático } \\
\text { de estudantes durante a construção de provas em um ambiente } \\
\text { de geometria dinâmica }\end{array}$ & Elen Andrea Janzen \\
\hline UERJ & 2012 & $\begin{array}{l}\text { Comunicação alternativa e formação inicial de professores para } \\
\text { a escola inclusiva. }\end{array}$ & Carolina RizzottoSchirmer \\
\hline UFBA & 2008 & $\begin{array}{l}\text { A formação de professores e a utilização das tecnologias de } \\
\text { informação e comunicação nos cursos de licenciatura da } \\
\text { Universidade do Estado da Bahia Campus II - Alagoinhas - } \\
\text { Bahia }\end{array}$ & $\begin{array}{l}\text { Daisy Oliveira da Costa Lima } \\
\text { Fonseca }\end{array}$ \\
\hline PUC-Rio & 2010 & $\begin{array}{l}\text { Letramento digital: um estudo sobre a formação de discentes do } \\
\text { curso de letras da UEPA }\end{array}$ & Elisa Maria Pinheiro de Souza \\
\hline USP & 2012 & $\begin{array}{l}\text { Um diálogo entre comunicação e educação: a formação inicial } \\
\text { de professores em sociedades midiáticas }\end{array}$ & Simone Rodrigues Batista \\
\hline UFRN & 2011 & $\begin{array}{l}\text { O lugar do estudo das mídias na formação de professores numa } \\
\text { perspectiva emancipatória }\end{array}$ & Márcia Barbosa da Silva \\
\hline UFRN & 2011 & $\begin{array}{l}\text { Entre telas, diálogos e estratégias: formação docente para a } \\
\text { mídia televisiva }\end{array}$ & Sandro da Silva Cordeiro \\
\hline $\begin{array}{l}\text { UNESP } \\
\text { Marília }\end{array}$ & 2012 & $\begin{array}{l}\text { Formação de professores de salas de recursos multifuncionais } \\
\text { para o uso de tecnologia assistiva }\end{array}$ & Eromi Izabel Hummel \\
\hline FEUSP/USP & 2009 & $\begin{array}{l}\text { A prática da pesquisa e mapeamento informacional } \\
\text { bibliográfico apoiados por recursos tecnológicos: impactos na } \\
\text { formação de professores }\end{array}$ & Claudio Fernando André. \\
\hline UNICAMP & 2006 & $\begin{array}{l}\text { A escrita no processo de formação continua do professor de } \\
\text { matemática }\end{array}$ & Maria Teresa Menezes Freitas \\
\hline UERJ & 2008 & $\begin{array}{l}\text { Formação e trabalho docente: os sentidos atribuídos às } \\
\text { tecnologias da informação e da comunicação }\end{array}$ & Ligia Karam Corrêa de Magalhães \\
\hline
\end{tabular}

$$
\text { Fonte: Elaborada pelos autores. }
$$

As teses apresentadas no quadro acima, selecionadas em um universo de 3469 teses, contidas do banco de dados do Grupo Horizonte, nos permitem verificar quantas versam sobre as tecnologias digitais presentes em cursos presenciais superiores de formação de professores. A figura 1 possibilita uma maior visualização das teses que versam sobre as tecnologias digitais presentes em cursos presenciais superiores de formação de professores. 


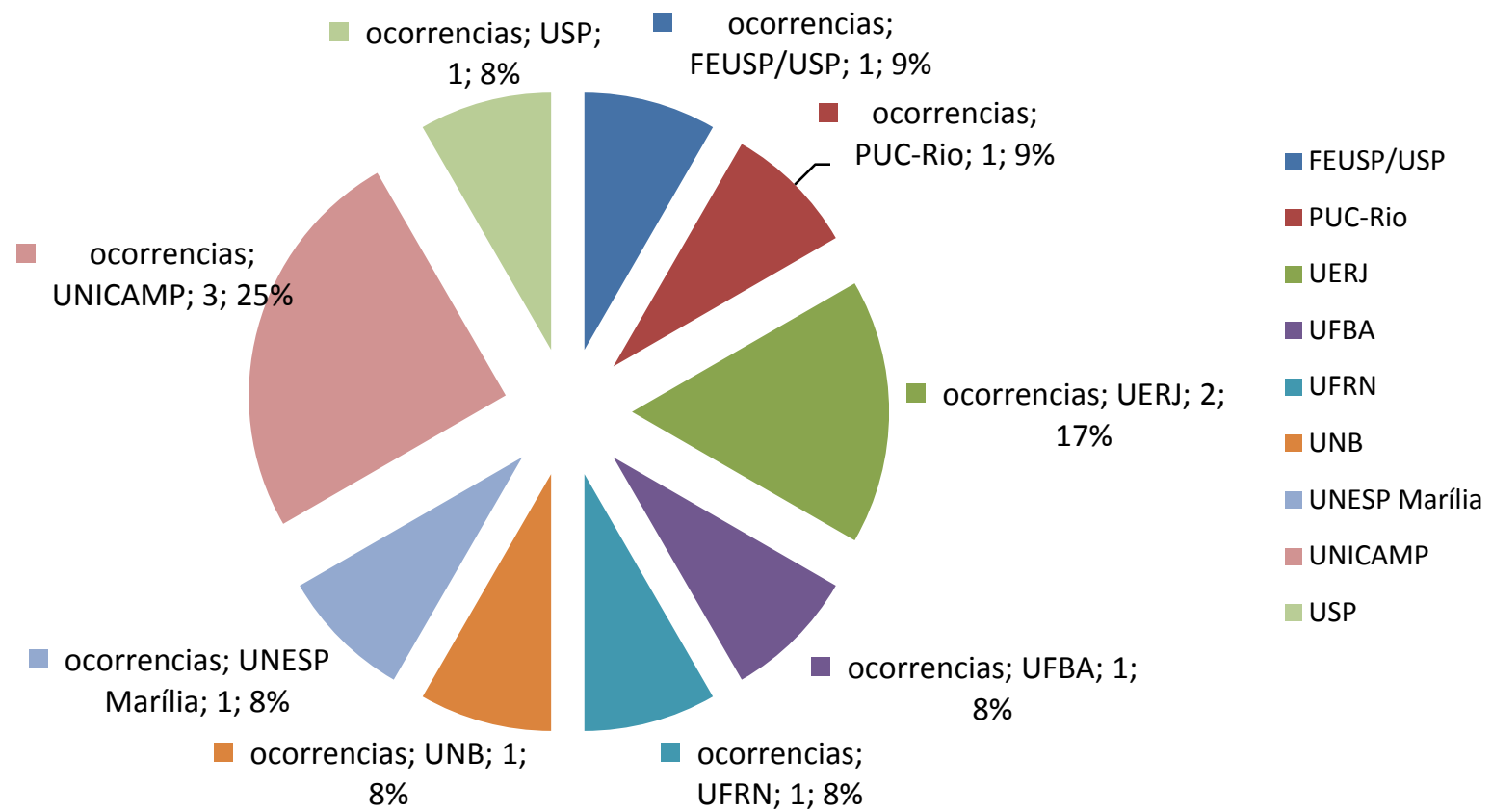

Figura 1: Instituições/ocorrências

Das vinte e seis instituições de educação superior, nove apresentaram teses relacionadas com o tema de nossa pesquisa, sendo que não é possível definir uma instituição que apresente um número muito expressivo de teses sobre o tema. A figura acima demonstra as instituições que apresentaram ocorrência e as respectivas quantidades.

Quadro 16: Ano/ocorrência das teses selecionadas

\begin{tabular}{|l|r|}
\hline ANO & OCORRENCIA \\
\hline 2005 & 1 \\
\hline 2006 & 1 \\
\hline 2008 & 2 \\
\hline 2009 & 2 \\
\hline 2010 & 1 \\
\hline 2011 & 3 \\
\hline 2012 & 3 \\
\hline Total & $\mathbf{1 3}$ \\
\hline
\end{tabular}

Fonte: Elaborada pelos autores.

Podemos observar no quadro 16 que o interesse pela temática tem aumentado gradativamente ao longo dos anos, o que se justifica pela ampliação do acesso às tecnologias digitais na educação, em todos os níveis educacionais, fator esse que pode ser atribuído principalmente aos investimentos governamentais como, por exemplo, o Programa Nacional de Tecnologia Educacional (ProInfo) do Ministério da Educação, que tem como objetivo a promoção da utilização do uso pedagógico da informática na rede pública de educação. É importante enfatizar, por fim, que algumas teses defendidas mais recentemente podem ainda não terem sido disponibilizadas no formato digital.

As teses selecionadas versam sobre utilização de mídias interativas em programas de formação de professores em exercício nas séries iniciais do Ensino Fundamental; a utilização da webconferência em um curso presencial de mestrado; o papel do professor de matemática no ambiente de geometria dinâmica; planejamento, implementação e avaliação da eficácia de um programa de formação inicial de professores para atuar com Tecnologia Assistiva ${ }^{8}$; utilização das TIC em cursos de licenciatura, letramento digital, 
formação inicial de professores em sociedades midiáticas; utilização de mídias na formação de professores na perspectiva emancipatória, possibilidade de tornar professores aptos para a leitura crítica da mídia televisiva; planejamento, desenvolvimento e avaliação de uma proposta de formação de professores para o uso dos recursos tecnológicos, no Atendimento Educacional Especializado, em Salas de Recursos Multifuncionais; a utilização de recursos tecnológicos para a prática da pesquisa e mapeamento informacional bibliográfico na formação de professores; estudo da escrita, na disciplina de Geometria, associada à utilização de tecnologias de informação e comunicação; centralidade atribuída às tecnologias da informação e da comunicação nas propostas de formação de professores e implicações no trabalho docente.

Das 3460 teses somente 13 mencionam a utilização de tecnologias digitais em cursos superiores presenciais, o que demonstra ainda uma enorme lacuna, uma vez que esses recursos que atualmente estão muito mais acessíveis e podem potencializar a prática pedagógica do futuro professor.

\section{Considerações Finais}

O presente trabalho buscou identificar quantas teses na área de educação mencionam a utilização de tecnologias digitais em cursos superiores presenciais de formação de professores, a partir das teses de 26 instituições de educação superior disponibilizadas digitalmente, abrangendo o período de 2002 a 2012. A coleta dos dados foi feita de forma coletiva, dando origem ao banco de dados do Grupo Horizonte (Grupo de Estudos e Pesquisas sobre Inovação em Educação, Tecnologias e Linguagens). $\mathrm{O}$ banco de dados contém 3469 teses.

Com a busca através dos termos chave Formação inicial, Licenciatura, Formação do pedagogo, Presencial, Formação de professores, Formação docente, totalizamos 338 teses. Passamos, então, a pesquisar nos resumos das 338 teses os seguintes termos: Tecnologia, Presencial, TIC, Internet, Mídia, CD/DVDs, Vídeo, Recursos, Virtual, Ambiente, Computador, Tablet, Web e Digital. Perfizemos 116 teses. Por fim, passamos à leitura detalhada dos resumos dessas 116 teses, selecionando as que estivessem de acordo com o nosso tema. Totalizamos, ao final, 13 teses.

No banco de dados pesquisado estão registradas teses de vinte e seis instituições de prestígio no Brasil, sendo que nove instituições apresentaram teses relacionadas com nossa pesquisa. Com base em nossos resultados, não é possível observar instituições que apresentem um número muito maior de teses que contemplem nosso tema em relação às demais instituições catalogadas.

Moran (2007) aduz as inúmeras possibilidades que combinam o melhor do presencial com as facilidades do virtual, "o importante é que os alunos aprendam de verdade no presencial e no on-line" (MORAN, 2007, p. 04). Nesse contexto, é esperado o aumento de pesquisas que versem sobre tecnologias digitais empregadas na educação presencial, inclusive, como foi nosso objetivo, nos cursos de formação de professores.

De acordo com os resultados obtidos no presente trabalho, em um universo de 3469 de 26 instituições somente 13 teses de nove instituições abordavam a questão das tecnologias digitais presentes em cursos presenciais superiores de formação de professores, o que demonstra uma lacuna diante do crescimento e popularização que as tecnologias digitais sofreram ao longo do período pesquisado (2002 a 2012), revolucionando diversos espaços sociais, permitindo a difusão do conhecimento e a postura crítica diante da possibilidade de comparação de múltiplos ângulos de uma mesma questão, o que representa um desafio para os futuros professores, mas também uma ferramenta primordial para a formação de alunos conscientes da possibilidade de sua atuação na sociedade.

\section{Notas}

1 Programa Um Computador por Aluno (PROUCA).

2 Vide <http://portaldoprofessor.mec.gov.br/conteu doJornal.html?idConteudo=17> Acesso em: 04 dez. 2013.

3 Disponível em http://www.anatel.gov.br/Portal/ exibirPortalNoticias.do?acao $=$ carregaNoticia\&cod igo $=30392$. Acesso em: $04 \mathrm{dez} .2013$.

4 A teledensidade é o indicador utilizado internacionalmente para demonstrar o número de telefones em serviço em cada grupo de 100 habitantes.

5 São entendidos como equipamentos móveis todos os aparatos eletrônicos que permitam o acesso a informações provenientes da internet.

6 Disponível em <http://www1.folha.uol.com.br /fsp/saber/sb0310201101.htm> Acesso em 05 
Dez. de 2013.

$7 \mathrm{O}$ termo ambiente foi usado por abranger ambientes virtuais, ambientes de aprendizagem, ambientes de ensino, dentro outros relacionados.

8 Vide a Portaria $\mathrm{n}^{\circ} 142$, de 16 de Novembro de 2006 do Comitê de Ajudas Técnicas.

\section{Referências}

ADORNO, T. W. Educação e Emancipação. Tradução Wolfgang Leo Maar - Rio de Janeiro: Paz e Terra, 1995. 4 ${ }^{\mathrm{a}}$. Ed.

ALONSO, C. A. Internet no Brasil - alguns dos desafios a enfrentar. Informática Pública, v. 4, n. 2, p. 169-184, 2002.

BRASIL. Coordenadoria Nacional para Integração da Pessoa Portadora de Deficiência. Acessibilidade. Brasília: CORDE, 2006.

BRECHT, B. Teatro completo, vol. 6. Rio de Janeiro: Paz e Terra, 1991.

GIORDAN, M. Computadores e linguagens nas aulas de CIÊNCIAS uma perspectiva sociocultural para compreender a construção de significados. Ljuí: Ed. Unijuí, 2008.

GONÇALVES, F. A. S.; CANESIN, C. A. Java applets para um software educacional distribuído em eletrônica de potência. 2002. Disponível em <http://www.scielo.br/scielo.php?pid=S0103-17592 002000300010\&script=sci_arttext.> Acesso em 17 Out. 2011.

LÉVY, P. As Tecnologias da Inteligência. O Futuro do Pensamento na Era da Informática. Editora 34. São Paulo. 1993. p. 7-19.

KONDER, L. Walter Benjamin: o marxismo da melancolia. 3. ed. Rio de Janeiro: Campus, 1999. $126 \mathrm{p}$.

PRENSKY, M. Digital natives, digital immigrants, part I. On the Horizon. Lincoln: NCB University. Press, v. 9, nº 5, 2001.
LION, G. C. Mitos e realidades na tecnologia educacional. In LITWIN, Edith (org.). Tecnologia educacional: política, histórias e propostas. Porto Alegre: Editora Artmed, 2001.

MILL, D. Mudanças de mentalidade sobre educação e tecnologia: inovações e possibilidades tecnopedagógicas. In: MILL, D. Escritos sobre educação: desafios e possibilidades para ensinar e aprender com as tecnologias emergentes. São Paulo: Paulus, 2013.

MORAN, J. M. Os modelos educacionais na aprendizagem on-line. S.1, 2007. Disponível em: < http://www.eca.usp.br/prof/moran/modelos.htm >. Acesso em 09 Dez 2013.

ROSA, R. Trabalho docente: dificuldades apontadas pelos professores no uso das tecnologias. Revista Encontro de Pesquisa em Educação. Uberaba, v. 1, n.1, p. 214-227, 2013.

SAWAYA, M. R. Dicionário de Informática \& Internet - Inglês/português. Editora Nobel, 1999.

SOUZA, F. F. Construção e avaliação de um ambiente virtual de aprendizagem voltado à Educação em Ciências, Química Verde $e$ Sustentabilidade Socioambiental. 2013, 101p. Dissertação (Mestrado em Educação). Universidade Federal de São Carlos. Local: UFSCar, São Carlos, 2013.

TARDIF, M.; RAYMOND, D. Saberes, tempo e aprendizagem do trabalho no magistério. Educação \& Sociedade, Campinas, ano XXI, n. 73, 2000.

VALENTE, J. A. Pesquisa, comunicação e aprendizagem com o computador. O papel do computador no processo ensino-aprendizagem. In: ALMEIDA, M. E. B.; MORAN, J. M. (Orgs.). Integração das tecnologias na educação. Brasília: Ministério da Educação, SEED, 2005, p. 22-31.

VERASZTO, E. V; SILVA, D; MIRANDA, N. A; SIMON, F. O. Tecnologia: buscando uma definição para o conceito. Prisma, n. 7, p. 60-85, 2008. 


\section{Sobre os autores}

Fábio Fontana Souza é Mestre em Educação pela UFSCar, doutorando em Educação pela UFSCar.

Maria Iolanda Monteiro é Doutora em Educação pela Universidade de São Paulo. Pós-doutorado na Faculdade de Educação da Universidade de Campinas. Professora da Universidade Federal de São Carlos.

Recebido em setembro de 2014.

Aprovado em maio de 2015. 